\title{
Aortic pulse wave velocity assessment in CMR: a novel method for transit time estimation
}

\author{
Antonella Meloni ${ }^{1,2^{*}}$, Heather M Zymeski ${ }^{2}$, Alessia Pepe ${ }^{1}$, Massimo Lombardi ${ }^{1}$, John C Wood ${ }^{2,3}$ \\ From 16th Annual SCMR Scientific Sessions \\ San Francisco, CA, USA. 31 January - 3 February 2013
}

\section{Background}

Aortic pulse wave velocity (PWV) is considered as the "gold standard" measurement of arterial stiffness and is commonly calculated as the ratio between the distance separating two locations along the artery and the transit time $(\Delta t)$ needed for the pressure or velocity wave to cover this distance. PWV is increasingly assessed by means of cardiovascular magnetic resonance (CMR). Our goal was evaluate the efficiency of a novel method for $\Delta t$ estimation, based on the principle of group delay (TT-GD method).

\section{Methods}

Flow curves were estimated from phase contrast (PC) images of 30 patients. The TT-GD method operates in the frequency domain and models the ascending aortic waveform as an input passing through a discrete-component "filter", producing the observed descending aortic waveform, so that the group delay (GD) of that filter represents the average time-delay. This method was compared with two previously described time-domain methods: TT-point using the half-maximum of the curves and TT-wave using cross correlation. In order to study the effect of the temporal resolution on $\Delta \mathrm{T}$ estimates, the original flow curves were downsampled of a factor of two, three and four.

\section{Results}

Mean $\Delta$ ts obtained with the three methods were comparable (TT-GD: $28.18 \pm 5.36 \mathrm{~ms}$, TT-point: $27.02 \pm 5.32 \mathrm{~ms}$, TT-wave: $26.93 \pm 4.41 ; \mathrm{P}=0.561$ ).

The TT-GD method was the most robust to reduced temporal resolution (Table 1).

While the TT-GD as well as the TT-wave produced comparable results for velocity and flow waveforms (coefficient of variability or $\mathrm{CoV}: 4.81 \%$ and 5.04 , respectively), the TT-point resulted in significant shorter $\Delta \mathrm{t}$ values when calculated from velocity waveforms $(\mathrm{CoV}=8.71 \%$, mean difference: $1.78 \pm 2.73 \mathrm{~ms}$ ).

The TT-GD method was the most reproducible, with an intra-observer variability of $3.38 \%$ and an inter-observer variability of $3.67 \%$.

\section{Conclusions}

Since the TT-GD method operates in the frequency domain, it was more robust to reduced temporal resolution than either of the time-domain methods. Moreover, it was more robust to the waveform type and more reproducible.

\section{Funding}

This work was part of National Institutes of Health trial supported by the National Heart Lung and Blood Institute grant \# 1 RO1 HL075592-01A1. 
Table 1 Influence of temporal resolution on the $\Delta$ ts estimated from flow curves.

\begin{tabular}{|c|c|c|c|}
\hline & Downsampling by 2 & Downsampling by 3 & Downsampling by 4 \\
\hline \multicolumn{4}{|c|}{ TT-GD } \\
\hline Best-fitting line: slope Intercept (ms) & $1.007 \pm 0.047-0.271 \pm 1.361$ & $0.929 \pm 0.0631 .891 \pm 1.810$ & $0.923 \pm 0.0883 .131 \pm 2.519$ \\
\hline$R$-squared for the linear fitting & 0.941 & 0.886 & 0.798 \\
\hline Difference, mean $\pm S D(m s)$ & $-0.08 \pm 1.34$ & $-0.10 \pm 1.83$ & $0.97 \pm 2.52$ \\
\hline$P$ (paired test) & 0.746 & 0.756 & 0.074 \\
\hline CoV (\%) & 3.33 & 4.52 & 6.57 \\
\hline$I C C$ & 0.985 & 0.970 & 0.937 \\
\hline Correlation, $r$ (P-value) & $0.970(P<0.0001)$ & $0.941(P<0.0001)$ & $0.893(P<0.0001)$ \\
\hline BA limits (ms) & -2.7 to 2.6 & -3.7 to 3.5 & -4.0 to 5.9 \\
\hline \multicolumn{4}{|c|}{ TT-POINT } \\
\hline Best-fitting line: slope Intercept (ms) & $0.722 \pm 0.1567 .483 \pm 4.287$ & $0.927 \pm 0.1871 .469 \pm 5.147$ & $0.506 \pm 0.21515 .093 \pm 5.921$ \\
\hline$R$-squared for the linear fitting & 0.434 & 0.467 & 0.165 \\
\hline Difference, mean $\pm S D$ (ms) & $-0.03 \pm 4.63$ & $-0.52 \pm 5.28$ & $1.74 \pm 6.6$ \\
\hline$P$ (paired test) & 0.971 & 0.597 & 0.159 \\
\hline $\operatorname{CoV}(\%)$ & 11.91 & 13.78 & 17.04 \\
\hline ICC & 0.798 & 0.794 & 0.559 \\
\hline Correlation, $r$ (P-value) & $0.659(P<0.0001)$ & $0.683(P<0.0001)$ & $0.406(P=0.026)$ \\
\hline BA limits (ms) & -9.1 to 9.0 & -10.9 to 9.8 & -11.2 to 14.7 \\
\hline \multicolumn{4}{|c|}{ TT-WAVE } \\
\hline Best-fitting line: slope Intercept (ms) & $0.917 \pm 0.0841 .637 \pm 2.303$ & $0.926 \pm 0.0961 .871 \pm 2.622$ & $0.809 \pm 0.1086 .175 \pm 2.939$ \\
\hline$R$-squared for the linear fitting & 0.808 & 0.768 & 0.668 \\
\hline Difference, mean $\pm S D$ (ms) & $-0.61 \pm 2.01$ & $-0.13 \pm 2.27$ & $1.04 \pm 2.66$ \\
\hline$P$ (paired test) & 0.108 & 0.757 & 0.040 \\
\hline $\operatorname{CoV}(\%)$ & 5.49 & 5.89 & 7.24 \\
\hline ICC & 0.944 & 0.935 & 0.889 \\
\hline Correlation, $r$ (P-value) & $0.899(P<0.0001)$ & $0.876(P<0.0001)$ & $0.818(P<0.0001)$ \\
\hline BA limits (ms) & -4.6 to 3.3 & -4.6 to 4.3 & -4.2 to 6.2 \\
\hline
\end{tabular}

\section{Author details}

${ }^{1}$ CMR Unit, Fondazione G.Monasterio CNR-Regione Toscana and Institute of

Clinical Physiology, Pisa, Italy. ${ }^{2}$ Department of Pediatrics, Division of

Cardiology, Children's Hospital Los Angeles, Los Angeles, CA, USA.

${ }^{3}$ Department of Radiology, Children's Hospital Los Angeles, Los Angeles, CA, USA.

Published: 30 January 2013

doi:10.1186/1532-429X-15-S1-E25

Cite this article as: Meloni et al: Aortic pulse wave velocity assessment

in CMR: a novel method for transit time estimation. Journal of

Cardiovascular Magnetic Resonance 2013 15(Suppl 1):E25.
Submit your next manuscript to BioMed Central and take full advantage of:

- Convenient online submission

- Thorough peer review

- No space constraints or color figure charges

- Immediate publication on acceptance

- Inclusion in PubMed, CAS, Scopus and Google Scholar

- Research which is freely available for redistribution

Submit your manuscript at www.biomedcentral.com/submit 